\title{
2 LA EXPRESIÓN CORPORAL Y SUS ALCANCES EN LA METO- DOLOGÍA ONTO-FENOMENOLÓGICA DE EDITH STEIN: SU RELEVANCIA PARA LA PREGUNTA POR LA MUJER*
}

DOI: $10.22199 /$ S07198175.2010.0001.00002

Anneliese MEIS ssps

\section{RESUMEN}

El cuerpo es material y es indispensable para vivir. Pero es algo más que físico también un cuerpo vivo que siente y piensa: es mi cuerpo vivo. Desde este presupuesto, podemos seguir el pensamiento de Edith Stein. El cuerpo es el centreo del espacio. Con él, me percibo y percibo el mundo. El cuerpo me permite expresar todo lo que siento desde la alegría hasta la ira. Cada expresión modifica mi cuerpo. El cuerpo me ayuda a entender a los demás, a tener empatía y me permite entonces entender al otro a través de las expresiones de su cuerpo. Así a través del cuerpo se llega a la profundidad del ser humano, propio y ajeno, que Edith Stein llama 'el alma del alma'.

Palabras claves: Edith Stein, cuerpo y corporalidad, expresión corporal, empatía

\section{BODILY EXPRESSION AND ITS IMPLICATIONS IN THE ONTO- PHENOMENOLOGICAL METHOD OF EDITH STEIN: AN IMPORTANT POINT FOR WOMEN'S ISSUES}

\section{ABSTRACT}

The body is material, and indispensable for living. But it is something more than just physical. It's also a body that lives, feels and thinks. It is my living body. Starting with this supposition, we can follow the thought of Edith Stein. The body is the center point of space. With it, I perceive myself and the world. The body allows me to express everything I feel, from joy to rage. Every expression modifies my body. The body helps me to understand others, to feel empathy and it allows me then to understand others through the expressions of their bodies. Thus, through the body, we access the depth of the human being, self and other, that Edith Stein calls "the soul of the soul".

Key words: Edith Stein, body, corporality, bodily expression, empathy. 
$\mathbf{S}_{i}$ bien la comprensión de la expresión corporal representa un eje transversal en todo el estudio Sobre el problema de la empatía de Edith Stein, autora muy apreciada por Juan Pablo II cuya respuesta a la pregunta por la mujer' se asemeja a la de esta santa mártir, gran pensadora y carmelita², su tratamiento se hace explícitamente en el capítulo III, donde la autora responde a la pregunta ¿Qué es el cuerpo vivo -Leib- y cómo se constituye "mi cuerpo vivo"? Intentaremos desglosar los aspectos más relevantes, tanto metodológicos como de contenido, de la expresión corporal y su relevancia para la pregunta por la mujer en continuidad con estudios anteriores ${ }^{3}$.

\section{Punto de partida metodológico, la realidad existente y su percepción}

Existo en un mundo de cuerpos físicos, en el cual hay fuera de mí sujetos vivenciantes y yo sé de esta vivencia. Podemos partir del fenómeno pleno, un sujeto síquico-físico, que se distingue de una cosa física, pues no sólo existo como cuerpo físico -Körper-, sino como cuerpo vivo -Leib-, al cual pertenece un yo que siente, piensa, quiere, cuyo cuerpo vivo no sólo está integrado en mi mundo fenoménico, sino es por su parte centro de tal mundo fenoménico, se encuentra frente a él y entra en intercambio con él.

* El presente breve estudio fue expuesto la Sesión 4 del 12.10.2009, en el Grupo de Reflexión Edith Stein, Facultad de Teología, que abordó el problema de la empatía en la obra de Edith Stein, Zum Problem der Einfühlung para dilucidar problemas metodológicos subyacentes a la pregunta por la mujer y su especificidad.

1 MEIS A., La mujer en el pensamiento de Juan Pablo II, Tierra Nueva 2 (2005), pp. 227-249: Cf. IDEM., El Misterio Trinitario en el pensamiento de Juan Pablo II, en VV.AA., Un Vigía de los tiempos. Diez miradas universitarias al pensamiento de S.S. Juan Pablo II , Ediciones Universidad Católica de Chile, Santiago 2005, pp. 89-126.

2 La vida excepcional de Edith Stein (1891-1942) está muy bien documentada, sobre todo a partir de la autobiografía y las cartas de la autora. Cf. HERBSTRITH W., El verdadero rostro de Edith Stein, Madrid 1990, $255 \mathrm{pp}$.

3 MEIS A., La cuestión de la especificidad de la mujer en Edith Stein (1891-1942), Teología y Vida 50 (2009), pp. 747-795. 
Podríamos investigar cómo todo esto se constituye según la conciencia, lo cual nos aparece más allá de la percepción externa de los cuerpos físicos. La percepción externa es un título para los actos por medio de los cuales el ser y acontecer numérico-espacial, cosificado llega a ser algo dado corporalmente, existiendo frente a mi ahora y aquí, mostrándome este lado o aquel, de tal modo que el lado de frente está ahí de modo específicamente corporal u originario, en comparación con los lados de reverso.

La expresión originariamente dado 'apresenta' - como suele decir Husserl - lo anímico, lo cual como 'lo dado junto con' está ahí como realidad ahora existente. Originarias son todas las experiencias propias como tales, pero no todas las experiencias son dadas originariamente; son originarias según su contenido: el recuerdo, la expectación, la fantasía no tienen su objeto presente delante de sí como corporalmente, sino sólo lo representan.

A este recuerdo neutralizante del presente, la representación de algo real, pero no dado de modo corporal se opone un recuerdo neutralizante del pasado y fantasías futuras. La diferencia entre vivencias ajenas y propias del yo ajeno y del yo propio no se confunden ni se identifican ya que la diferencia entre el vivenciar ajeno y propio no se anula, pues su originariedad se atestigua en mi no-originariedad ya por el mismo movimiento externo del cuerpo físico. Por la empatía siento mi alegría y constato que la del otro es la misma, verificando paso por paso la identidad con mi vivencia corporal viva. Sin embargo, así no llego al fenómeno de la vivencia ajena sino a la mía propia: falta la parte intermedia, la vivencia ajena.

A esto responde Scheler que la percepción interna no es percepción de sí mismo, es decir, de nuestro cuerpo vivo. En virtud de una "disposición inexplicable de nuestro 'espíritu' o de un 'instinto natural' pensamos en una vida consciente ligada a ciertos cuerpos físicos. "Primeramente podemos considerar la unidad individual de la psique en cuanto tal, procediendo del cuerpo vivo y de las relaciones psicofísicas", pero de hecho no es posible, lo cual conduce a la pregunta ¿qué es el cuerpo vivo?

\section{2. ¿Qué es el cuerpo vivo y cómo se constituye 'mi cuerpo vivo'?}

El cuerpo vivo nos está dado. Para ver como "este darse del cuerpo vivo" se constituye partimos de nuevo de la esfera que constituye los fundamentos de todas nuestras investigaciones: la conciencia pura, y preguntamos: ¿Cómo se constituye mi cuerpo vivo para mí en la conciencia? "Por un lado tengo dado mi cuerpo físico 
en actos de percepción externa. Pero si hiciéramos por una vez la ficción de lo que tuviéramos dado sólo de esta manera, entonces se constituye para nosotros un objeto harto extraño. Una cosa real, un cuerpo físico cuyas series motivadas de apariencias muestran notables lagunas, que me retiene su cara oculta con una obstinación aún mayor que la de la luna, que me hace burla en tanto que me invita a contemplarlo por caras siempre nuevas, y tan pronto como quiero secundar su requerimiento oculta estas caras ante mí. Es cierto que lo que se sustrae a la mirada es alcanzable para la mano que tantea; pero precisamente esta relación entre ver y palpar es aquí distinta respecto a todas las demás cosas.

“Frente a esta singular imperfección del cuerpo físico percibido exteriormente hay otra peculiaridad...Este aproximar y alejar el movimiento de mi cuerpo físico y de las demás cosas, se atestigua en un cambio de las series de apariencias de aquellas cosas. $Y$ no es en absoluto previsible cómo se debe llegar a una distinción entre ambos casos (entre el movimiento de las otras cosas y el de mi cuerpo físico) o, en general, a la aprehensión del movimiento del propio cuerpo físico, mientras nos atengamos a nuestra ficción de que nuestro cuerpo físico se constituye sólo en percepción externa y no propiamente como cuerpo vivo. ... Pero el cuerpo vivo es un objeto dado a mí en series de apariencias que sólo son variables dentro de muy estrechos límites y, mientras mantenga los ojos abiertos, está continuamente ahí, con una insistencia inamovible, siempre en la misma aferrable proximidad como ningún objeto: él está siempre 'aquí', mientras que todos los demás objetos están siempre 'alli'".

“Más aquí hemos alcanzado ya el límite de nuestra ficción y nos vemos obligados a superarla. Pues incluso cuando cerramos fuertemente los ojos y extendemos las manos lejos de nosotros de modo que ningún miembro toque en absoluto al otro, de suerte que no podamos ni coger ni ver el cuerpo vivo, tampoco entonces nos desembarazamos de él, también entonces está inevitablemente ahí en plena 'corporalidad propia' y nos encontramos indisolublemente ligados a él. Precisamente esta ligazón, la pertenencia a mí, no se podría constituir nunca en la percepción externa. Un cuerpo vivo sólo percibido externamente siempre sería sólo un cuerpo físico especialmente clasificado, singularizado, pero nunca 'mi cuerpo vivo'. Veamos entonces cómo llega éste a ese nuevo darse".

“Entre los componentes efectivos de la conciencia, de esa región insuprimible del ser, se encuentran las sensaciones como una especificación de la categoría superior 'vivencia'. La sensación de presión, de dolor o de frío es algo tan absolutamente dado como la vivencia de juicio, de voluntad, de percepción, etc. Sin embar- 
go, la sensación está peculiarmente caracterizada frente a todos estos actos: ella no emana como aquellos, del yo puro; nunca adopta la forma del 'cogito' en el que el yo se dirige a un objeto, por tanto nunca puedo -reflexionando sobre ella- encontrar al yo en ella, sino que ella está siempre en un 'dónde', está localizada espacialmente, apartada del yo, quizá muy próxima a él, pero nunca en él. Y este 'donde' no es ningún lugar vacío en el espacio, sino un algo que llena el espacio; y todos estos algo en los que tienen lugar mis sensaciones se fusionan en una unidad, la unidad de mi cuerpo vivo, son lugares mismos del cuerpo vivo".

“Dentro de este darse uniforme por el que el cuerpo vivo está ahí para mí en todo momento como un todo, se muestran diferencias. Las distintas partes del cuerpo vivo que se constituyen para mí según la sensación están a una distancia distinta respecto de mí". "Cuando hablo de apartamiento de 'mí', éste es un modo inexacto de expresión; no puedo propiamente constatar una distancia del 'yo', que es in-espacial y está fuera de localización, sino que refiero las partes de mi cuerpo vivo, y sucesivamente todo lo espacial fuera de él, a un 'punto cero de la orientación' al que envuelve mi cuerpo vivo. Este punto cero no es localizable con exactitud geométrica en un lugar de mi cuerpo físico, además no es el mismo para todos los datos, sino que para los datos visuales está situado en la cabeza, en el cuerpo vivo central para los táctiles." "Esta distancia de las partes del cuerpo físico respecto de mí es, no obstante, fundamentalmente diferente de la distancia de otras partes entre sí y de mí. La distancia de las partes de mi cuerpo vivo respecto a mí es completamente incomparable con la distancia del cuerpo físico ajeno respecto a mí".

“El cuerpo vivo como un todo está en el punto cero de la orientación, todos los demás cuerpos están fuera. El 'espacio corporal' y el 'espacio externo' son completamente distintos el uno del otro. Sólo percibiendo externamente no llegaría al primero, sólo 'percibiendo corporalmente' no llegaría al otro. Pero en tanto que mi cuerpo vivo se constituye de doble manera -como cuerpo vivo sintiente (percibido corporalmente) y como cuerpo físico del mundo externo percibido externamente- $y$ en esta doble presentación es vivenciado como el mismo, conserva un lugar en el espacio externo, llena una parte de ese espacio".

“Todavía hay algo que decir sobre la relación entre sensación y 'percepción corporal'. El análisis de las sensaciones suele presentarse ordinariamente en otras correlaciones. Se las suele mirar como aquello que nos "da" el mundo externo y en este sentido se distingue 'sensación' y 'sentido' o 'contenido de sensación' y 'sensación como función'... El rojo del objeto está 'percibido' y entre percepción y 
percibido, sí debo distinguir. En el análisis de las percepciones soy conducido a los 'datos de sensación' y puedo llegar a ver la percepción de cualidades como 'objetivación de datos de sensación'; sin embargo, con ello no se convierten las cualidades en sensaciones ni las sensaciones en cualidades, mas tampoco en actos de donación. Como componentes de la percepción externa, ellas no son elementos ulteriormente analizables.

“Si ahora consideramos la sensación según su lado vuelto al cuerpo vivo, entonces encontramos un estado fenomenológico de hechos completamente análogo. Puedo hablar tan poco de un cuerpo vivo 'sentido' como de un objeto del mundo externo 'sentido', pero también aquí es menester una concepción objetivadora. Un punto de un dedo toca la mesa: lo que hace especialmente íntimo el enlace de sensación y percepción es el hecho de que el cuerpo vivo está dado como sintiente, y las sensaciones se dan en el cuerpo vivo". El cuerpo vivo 'percibido externamente' y el 'percibido corporalmente' están dados como el mismo. Esto requiere aún una aclaración más detallada. Yo no sólo veo mi mano y percibo la misma mano corporal como sintiente, sino que 'veo' también los campos de sensación de la mano que se han constituido para mí en percepción corporal, y por otro lado, en tanto que destaca partes de mi cuerpo vivo, tengo al mismo tiempo una 'imagen' de la parte correspondiente del cuerpo físico: lo uno está dado con lo otro, aunque no percibido. Tenemos un análogo exacto en el área de la percepción externa. No sólo vemos la mesa y palpamos su dureza, sino que también 'vemos' su dureza". Los vestidos en los cuadros de Van Dyck no sólo tienen el brillo de la seda, sino también de la seda tersa y de la seda suave.

Los psicólogos denominan a este fenómeno fusión, y la mayor parte de las veces lo reducen a 'mera asociación'. En el 'mera' reside la tendencia psicológica a ver el explicar como un interpretar, a declarar el fenómeno explicado como un 'producto subjetivo' sin 'significado objetivo'. No podemos hacer nuestra esta concepción. El fenómeno permanece fenómeno. Es muy hermoso que se lo pueda explicar, pero la explicación no le añade ni le quita nada. La visibilidad de las cualidades táctiles permanecería, pues, y no perdería nada de dignidad si se pudiese explicar por medio de asociaciones. Pero no creemos posible tal explicación porque contradice el 'fenómeno' de la asociación. La forma típica de asociación vivenciada es "algo que me recuerda de algo". Así, por ejemplo, la visión del canto de la mesa está asociada con el recuerdo de que una vez me he hecho daño con él. Pero la agudeza de este canto no está recordada, sino vista. Por poner todavía un ejemplo instructivo: veo la dureza del azúcar y sé o me acuerdo de que es dulce; no me acuerdo de que es dura y no veo que es dulce...el cuerpo vivo visto no nos recuerda que puede ser el 
lugar visible de múltiples sensaciones, tampoco es meramente un cuerpo físico que ocupa el mismo espacio que el cuerpo vivo dado como sintiente en la percepción corporal, sino que está dado como cuerpo vivo sintiente.

“Hasta ahora hemos considerado al cuerpo vivo sólo en reposo. Ahora podemos dar un paso más. Indagamos el caso de que yo (es decir, mi cuerpo vivo como un todo) me muevo a través del espacio... a la percepción del movimiento propio edificado sobre sensaciones varias se añade, como completamente nueva, la vivencia del 'yo me muevo', que es completamente diferente del movimiento corpóreo percibido desde fuera....en adelante el 'yo me muevo' es 'co-visto' en el movimiento de una parte del cuerpo físico, el movimiento corpóreo no visto es comprendido en la vivencia del 'yo me muevo'... Queda la posibilidad de un yo sin cuerpo vivo. En cambio es absolutamente imposible un cuerpo vivo sin yo. Imaginar mi cuerpo vivo abandonado por el yo ya no quiere decir imaginar mi cuerpo vivo, sino un cuerpo físico que se le asemeja rasgo a rasgo, mi cadáver. ..El cuerpo vivo está por naturaleza constituido por sensaciones, las sensaciones son componentes reales de la conciencia y como tales, pertenecientes al yo. ¿Cómo habría, pues, de ser posible un cuerpo vivo que no fuese cuerpo vivo de un yo?"

“Esta dependencia de los influjos del cuerpo vivo propia de las vivencias es una característica esencial de lo anímico. Todo lo psíquico es conciencia corporalmente ligada, y en este terreno se distinguen las vivencias esencialmente psíquicas... de aquellas que llevan en sí extra-esencialmente el carácter físico, la 'realizaciones de la vida espiritual'. El alma, como la unidad sustancial que se manifiesta en las vivencias psíquicas singulares, está consolidada-como muestran el fenómeno descrito de la 'causalidad psico-física' y la esencia de las sensaciones- en el cuerpo vivo, constituye con él el individuo psico-físico... En el instante en que se aparta el pensamiento del cuerpo vivo desaparecen esos fenómenos, pero permanece el acto espiritual. Un espíritu puro también se puede asustar, pero su entendimiento no se bloquea. Siente alegría y piensa en toda su profundidad, pero ellas no ejecutan ningún efecto".

\section{El fenómeno de la expresión}

La expresión de los sentimientos aparece como un fenómeno nuevo. “Yo me ruborizo de vergüenza, aprieto colérico el puño, frunzo el ceño enfadado, gimo de dolor, exulto de alegría. La relación entre sentimiento y expresión es completamente distinta a la que hay entre sentimiento y síntoma físico concomitante. Ahora no advierto un provenir causal de las vivencias físicas desde las psíquicas, ni mucho menos una mera simultaneidad de ambas, sino que siento, en tanto que experimento sentimien- 
to, cómo él termina en una expresión o la libera desde sí". Según su esencia pura, el sentimiento es algo no cerrado en sí, está en cierto modo cargado con una energía que debe llegar a descargar, esta descarga es posible de diversas maneras..."los sentimientos liberan desde sí o motivan actos de voluntad y acciones. Exactamente la misma relación hay entre sentimiento y fenómeno expresivo. El mismo sentimiento que motiva un acto de voluntad puede también motivar un fenómeno expresivo. Y el sentimiento prescribe según su sentido cuál expresión y qué acto de voluntad puede motivar: por esencia tiene que motivar siempre algo, debe llegar siempre a la "expresión"; sólo que son posibles diversas formas de expresión. No anda lejos la objeción de que, muy a menudo en la vida, aparecen sentimientos sin que motiven un acto de voluntad o una expresión corporal".

Por ser 'personas civilizadas' debemos 'dominarnos', reprimir la expresión corporal de nuestros sentimientos. Queda la escapatoria de 'desahogarse' con un deseo. 0 se pueden realizar en la fantasía las acciones para hacer las cuales uno está impedido en la realidad. Este tipo peculiar de expresión precisaría una clarificación amplia: los sentimientos influyen en la 'reproducción de las representaciones'. Todavía queda otra posibilidad de expresión: aquella a la que recurre el hombre 'controlado', el que aparenta una semblante comedido por consideraciones sociales 0 éticas o estéticas: el sentimiento puede liberar desde sí un acto de la reflexión que lo convierte a él mismo en objeto. La vivencia 'termina' en este acto de la reflexión como en un acto de voluntad o expresión corporal -la reflexión fría. "El resultado de nuestra consideración hasta ahora es que el sentimiento pide, según su esencia, una expresión, y los distintos tipos de expresión son distintas posibilidades esenciales". "Entre sentimiento y expresión hay una conexión esencial y de sentido, no una conexión causal. Y, como las otras formas posibles, también la expresión corporal está vivenciada como procedente del sentimiento y conforme a su sentido, y por medio de él está determinada. Pero entonces no sólo siento cómo afluye el sentimiento a la expresión y se 'descarga' en ella, sino que a la vez tengo dada esta expresión en una percepción corporal”.

“La sonrisa en la que mi alegría se exterioriza según la vivencia me está dada, a la vez como una distorsión de mis labios. Al vivir en la alegría también está vivenciada su expresión según el modo de la inactualidad, no soy -como se suele decirconsciente de ella. Si luego dirijo mi atención al cambio de mi cuerpo vivo, me aparece como efectuado por el sentimiento. Junto a la unidad de sentido vivenciada se constituye, pues, una conexión causal entre sentimiento y expresión. La expresión se vale de la causalidad psicofísica para realizarse en un individuo psicofísico. En la percepción corporal se desmonta la unidad vivenciada de vivencia y expresión, 
la expresión es separada como un fenómeno relativamente autónomo. Con ello se hace, a la vez, producible por sí -sonrisa aparentada, expresión de cólera. Hace falta una mirada atenta para hacer de la expresión percibida corporalmente objeto intencional en sentido riguroso. También la expresión sentida, si bien vivenciada según el modo de la actualidad, requiere todavía una mirada especial para convertirse en objeto aprehendido, una mirada que no es tránsito de la inactualidad a la actualidad. Esta es una particularidad de todos los actos no-teoréticos y de sus correlatos".

“Que yo pueda objetivar los fenómenos de expresión vivenciados y aprehenderlos como expresión es una condición de posibilidad más para producirlos arbitrariamente. Aun así, la modificación corporal que se parece a una expresión no se da como ella misma. El fruncir el ceño por enfado y el fruncir el ceño para simular enfado son claramente diferenciables entre sí, incluso cuando paso de la percepción corporal a la percepción externa. En tanto que los fenómenos de expresión aparecen como afluencia de los sentimientos son, a la vez, expresión de las propiedades anímicas que en ellos se manifiestan: la mirada rabiosa, por ejemplo, delata un temperamento -Gemütsart- fuerte...También las vivencias de la voluntad tienen un alto significado para la constitución de la unidad psicofísica. Los demás fenómenos corporales de expresión que se toman en consideración no me parecen ser expresión del acto de voluntad mismo, sino de los componentes de sentimiento contenidos en la compleja vivencia de voluntad...estos movimientos son una expresión del sentimiento resultante de la resolución de la voluntad. La voluntad misma no tiene una expresión en este sentido. Pero, como el sentimiento, tampoco la voluntad está cerrada en sí, sino que requiere una repercusión. Así como el sentimiento libera desde sí o motiva el acto de voluntad (u otra posible 'expresión' en un sentido amplio), así se exterioriza la voluntad en la acción -fiat/fieri-..."

La "voluntad reina sobre el alma y sobre el cuerpo vivo, aun cuando no absolutamente ni sin experimentar denegación de la obediencia. ¿Es este actuar del querer y del tender sobre el alma y el cuerpo vivo causalidad psicofísica o tenemos aquí la muy discutida causalidad desde la libertad, la ruptura de la cadena causal 'sin lagunas'. Acción es siempre creación de algo que no es... Pero lo propiamente creativo del acto de voluntad no es ningún actuar causal; todas aquellas relaciones causales son extraesenciales a la voluntad, ésta se deshace de ellas tan pronto como deja de ser voluntad de un individuo psicofísico y, sin embargo, sigue siendo voluntad... es común a ambos, al querer y al tender, la capacidad de valerse de la causalidad psicofísica; sin embargo, sólo del yo volente se puede decir que es señor del cuerpo vivo". 


\section{La transición al individuo ajeno}

Cabe recordar que "Hay que entender por un yo individual o individuo: un objeto unitario en el que la unidad de conciencia de un yo y un cuerpo físico se juntan inseparablemente, por lo que cada uno de ellos adquiere un nuevo carácter; el cuerpo aparece como cuerpo vivo, la conciencia, como alma del individuo unitario. La unidad se atestigua en que ciertos procesos se dan como pertenecientes al alma y al cuerpo vivo a la vez (sensaciones, sentimientos comunes); además, en el enlace causal de procesos físicos y psíquicos y de la relación causal mediada por ellos entre el alma y el mundo externo real. El individuo psicofísico como totalidad es un miembro en el entramado de la naturaleza". "El cuerpo vivo está caracterizado frente al cuerpo físico por el hecho de que es portador de campos de sensación, se encuentran en el punto cero de la orientación del mundo espacial, es capaz de movimiento libre y está constituido con órganos móviles, es campo de expresión de las vivencias del yo que le pertenece e instrumento de su voluntad. Hemos obtenido todas estas características a partir de la consideración del individuo propio. Ahora hay que mostrar cómo se constituye para nosotros el ajeno".

Primero, cabe comprender el cuerpo vivo ajeno como cuerpo vivo, lo que lo distingue frente a otros cuerpos físicos. ¿Cómo nos están dados los campos de sensación? De los propios tenemos -como vimos- un darse originario en la 'percepción corporal'. Además los tenemos 'codados' en la percepción externa de nuestro cuerpo físico de aquella manera completamente peculiar en la que lo no percibido mismo puede existir junto con lo percibido. $Y$ de la misma manera existen los campos de sensación del otro para mí, el cuerpo vivo ajeno es 'visto' como cuerpo vivo. Este tipo de presentación la llamamos 'cooriginariedad', al ocuparnos de la percepción de la cosa. No originariamente y no como propias, sino 'con' exactamente en el modo de la empatía.

La posibilidad de la empatía de sensación (con precisión debería decirse 'endosensación' -Einempfindung-) está garantizada por la comprensión del cuerpo vivo propio como cuerpo físico, y del cuerpo físico propio como cuerpo vivo, en virtud de la fusión de percepción externa y percepción corporal. Si la magnitud de mi mano (longitud, anchura, proporción, etc.) me estuviera dada como constante inmutable, entonces tendría que fracasar el intento de empatía con toda mano de otra condición por la oposición de ambas; pero de hecho también resulta muy bien la empatía con manos de varones y de niños que son diferentes de la mía. Mi cuerpo físico y sus miembros no están precisamente dados como tipo fijo, sino como realización fortuita de un tipo variable dentro de límites fijos. Este tipo, por otra parte, ha de 
permanecer conservado. Sólo con cuerpos físicos de este tipo puedo empatizar, sólo a ellos puedo considerar como cuerpos vivos.

Con ello no está dada todavía una delimitación clara. Hay tipos de distinto grado de generalidad, y a ellos corresponden distintos grados de posibilidad de empatía. El typos "cuerpo humano no delimita el dominio de mis objetos de empatía, dicho con más exactitud, de lo que me puede estar dado como cuerpo vivo, pero delimita bien un dominio dentro del cual es posible un grado completamente determinado de cumplimiento empatizante. En el caso de la empatía con la mano ajena existe la posibilidad de un cumplimiento, aun cuando no 'adecuado', sí amplio sin embargo: lo que yo siento como no-originario se puede corresponder punto por punto con el sentir originario del otro. Y cuanto más nos alejamos del typos hombre, más disminuye el número de posibilidades de cumplimiento. En la comprensión de los cuerpos vivos ajenos como del mismo tipo que el perteneciente a mí se nos ofrece un buen sentido del discurso sobre el 'analogizar' que se da en la aprehensión de otro. Este analogizar tiene en verdad poco que ver con 'inferencias por analogía'. También la "asociación por semejanza, que Volkel, entre otros, destaca como importante para la empatía, se presenta como aprehensión de un caso aislado de tipo conocido. Para comprender un movimiento...tengo que 'trabarlo' primero con otros movimientos similares que me resultan conocidos. Según nuestra concepción, esto significa que tengo que encontrar en él un tipo conocido.

Llegamos al segundo constituens del cuerpo vivo a su posición en el punto cero de la orientación. Con la orientación hemos avanzado un enorme tramo en la constitución del individuo ajeno, pues con ella está empatizada, para el yo que pertenece al cuerpo vivo que siente, la plena totalidad de las percepciones externas conforme a cuya esencia se constituye el mundo espacial. De un sujeto que tiene sensaciones se ha llegado a uno que ejecuta actos. De tal modo que la imagen ajena del mundo modifica la propia, siendo la empatía de tal forma condición de posibilidad de la constitución del individuo propio. "A partir del punto cero de la orientación obtenida en la empatía tengo que considerar mi propio punto cero como un punto del espacio entre muchos, no ya como punto cero. Y a la vez, con ello -y sólo por ello- aprendo a ver mi cuerpo vivo a la manera de un cuerpo físico como los demás, mientras que en la experiencia originaria me está dado sólo como cuerpo vivo y por lo demás -en la percepción externa- como un cuerpo físico imperfecto diferente de todos los otros. En la 'empatía reiterada' comprendo de nuevo aquel cuerpo físico como cuerpo vivo, y sólo así me estoy dado a mí mismo en sentido pleno como individuo psicofísico para el que es constitutivo el estar fundado en un cuerpo físico. El mundo que veo empáticamente es mundo existente tal que está puesto como aquel 
percibido originariamente. El mundo percibido y el mundo dado según la empatía son el mismo visto diversamente. Se constituye en la experiencia intersubjetiva.

Hemos llegado a conocer el cuerpo vivo ajeno como portador de campos de sensación y como centro de orientación del mundo espacial, y ahora encontramos un constituens más en su libre movilidad.

\section{El cuerpo vivo ajeno como portador del fenómeno de la expresión}

No cabe duda de que con el hecho del "cuerpo vivo ajeno como portador de fenómeno de expresión", "Hemos llegado a conocer el cuerpo vivo ajeno como portador de una vida anímica que, en él, 'observamos' de determinada manera. Todavía falta un grupo de fenómenos que nos abren otra región de la psique de manera peculiarmente caracterizada. Cuando 'veo' la vergüenza 'en' el ruborizarse, el disgusto en el fruncir el ceño, la cólera en el puño apretado, entonces se trata de un fenómeno distinto de cuando observo en el cuerpo vivo ajeno su estrato sensible o co-percibo las sensaciones y los sentimientos vitales del otro individuo. Allí aprehendo lo uno con lo otro, aquí veo lo uno a través de lo otro. En el nuevo fenómeno está lo anímico no sólo co-percibido con lo corporal, sino expresado a través de ello, la vivencia y su expresión están en una conexión que encontramos descrita en Vischer y Lipps.

Finalmente, la diferencia capital: las palabras remiten al objeto a través del medium del significado, mientras que la señal no tiene ningún significado en absoluto, sino sólo la función del significar. Y las palabras no remiten simplemente al estado de cosas como la señal; lo que forma parte de ellas no es el estado de cosas, sino su modelo lógico-categorial. Las palabras no designan, sino que expresan, y lo expresado ya no es lo que antes había. Desde luego que esto también es verdad cuando lo expresado es algo psíquico. Si alguien me dice que está triste entiendo el sentido de las palabras. La tristeza de la que ahora sé no está 'viva' ante mí como dato de percepción. Se parece tan poco a la tristeza aprehendida en el símbolo como aproximadamente la mesa de la que oigo hablar a la parte posterior de la mesa que veo. En un caso me encuentro en la esfera apofática -en la región de las proposiciones y los significados-; en el otro caso, en contacto intuitivo inmediato con la esfera de los objetos. El significado es siempre universal; para entender qué objeto está mentado hic et nunc hace falta siempre que se dé el fundamento intuitivo sobre el cual se constituyen las vivencias de significado.

En el símbolo no hay semejante estrato intermedio entre vivencia expresada y modificación corporal expresiva. Pero en ambos casos hay algo común en virtud 
de lo cual se impone siempre de nuevo la designación de 'expresión' para los dos. Justamente esto es lo que constituye como lo otro la unidad de un objeto, pues la expresión desligada de la conexión con lo expresado ya no es el mismo objeto (a diferencia del cuerpo físico de la señal) ya que la expresión procede de la vivencia y se ajusta al material expresado. Estas relaciones son simples en la expresión corporal, en cierto sentido están duplicadas en la expresión verbal (palabra-significado-objeto, y correlativamente: tenencia del objeto, mentar o significar lógico y designación lingüística).

La función de expresar en virtud de la cual aprehendo en la expresión la vivencia expresada se realiza siempre en la vivencia de la procedencia de la expresión desde lo expresado, como ya hemos descrito en un lugar precedente (usando también allí 'expresión' en un sentido ya ampliado). En el caso del comprender, este vivenciar no es originario sino empatizado. Sin embargo, hay que distinguir aquí entre la expresión verbal y la expresión corporal. La comprensión de la expresión corporal se constituye sobre la aprehensión del cuerpo vivo ajeno, que ya está comprendido como cuerpo vivo de un yo. Yo me transfiero dentro del cuerpo vivo ajeno, realizo la vivencia que con el semblante correspondiente me estaba dada ya como vacía y vivencio cómo ella termina en aquella expresión. Con la palabra es posible, como vimos, un prescindir del individuo hablante. Yo mismo tengo una aprehensión originaria del significado, de ese objeto ideal, en la transición comprensiva de la palabra al significado, y mientras permanezco en esta esfera no tengo necesidad del individuo ajeno y no necesito coejecutar sus vivencias empatizando. Y también es posible mediante la vivencia originaria un cumplimiento intuitivo de lo mentado; puedo hacer que venga a darse a mi mismo el estado de cosas sobre el que la proposición afirma algo. ..Sólo si quiero tener la intuición en la que el hablante apoya su afirmación y en el que completa su vivencia de expresión tengo necesidad de la empatía.

Pero ¿qué pasa si de la palabra partieran todavía otros caminos? La puerta hacia el significado es el tipo puro de la palabra; pero éste siempre se nos presenta... en una envoltura terrena, en habla, en escritura o impreso. Entonces atrae el interés hacia sí y con esto, a la vez, hacia la persona hablante. Ella aparece como exteriorizando o comunicando las palabras, quizá como comunicándome a mí. En el último caso, las palabras 'deben' referirme a algo. entonces ya no son mera expresión de algo objetual, sino al mismo tiempo exteriorización o manifestación de los actos de la persona que confieren sentido, así como de las vivencias que están en la base, por ejemplo de una percepción... sin embargo, tampoco en su función manifestativa pueden ser designadas las palabras como símbolos: primero, porque ellas no 
constituyen el fundamento único ni tampoco el principal para la aprehensión de las vivencias correspondientes; segundo, porque estas vivencias son aprehendidas no en ellas, sino a partir de ellas, y además se reexponen de una manera totalmente distinta de lo dado simbólicamente. Como mucho se podría decir que al hablar se manifiesta el expresarse con la misma vivacidad que un afecto en su movimiento expresivo, pero no las vivencias mismas manifestadas.

Si después de esta caracterización del darse del símbolo nos queda claro una vez más lo que lo distingue del mero 'estar co-ofrecido' lo psíquico considerado hasta ahora, entonces vemos que en el nivel del transferirse dentro de otro empatizando es vivenciado aquel proceder de lo externamente percibido desde lo 'copercibido' en el primer nivel, lo cual faltaba en los casos anteriormente considerados... No se trata de la relación causal -el darse un suceso motiva un progresar hacia el darse del otro: aquí "el proceder de una vivencia desde otra es vivenciado en la más pura inmanencia sin el rodeo por la esfera del objeto. Llamaremos a este proceder vivenciado 'motivación'. Todo lo que se acostumbra designar como 'motivación' se presenta como un caso especial de esta motivación: la motivación del obrar mediante el querer, del querer mediante un sentir sentimiento, pero también del mismo modo el proceder de la expresión desde la vivencia. También hay que comprender así la motivación en la percepción de la que Husserl habla, el deslizarse de un darse a otro darse el objeto. No se sostiene la motivación como causalidad de lo psíquico.

“Solemos designar la relación de motivación, en contraste con la causal, como comprensible o plena de sentido. Comprender no significa otra cosa que vivenciar el paso de una parte a otra dentro de una totalidad de vivencia (no significa tener como objeto) y todo lo objetivo, todo sentido del objeto, se constituye sólo en vivencias de esta clase. Una acción es unidad de comprensión o de sentido porque las vivencias parciales que la constituyen vivencia y expresión una totalidad de comprensión. Una expresión la entiendo, mientras que una sensación sólo puedo traérmela a dato. Así, mediante el fenómeno de la expresión, soy introducido en los entramados de sentido de lo psíquico y con ello adquiero, a la vez, un medio importante para la corrección de los actos de empatía.

Aquello que aboliera la unidad de un sentido debe basarse en el engaño. Pero la posibilidad de corrección va más allá. No sólo comprendo las vivencias singulares y los entramados de sentido singulares, sino que los tomo -como mis propias vivencias en la percepción interna- como manifestación de cualidades individuales y de su portador. De esta manera, en actos de empatía se constituye para nosotros el 
individuo según todos sus elementos. Como en cualquier experiencia, también aquí son posibles los engaños, pero, como en todas partes, también aquí los engaños sólo se pueden desenmascarar por medio de actos experienciales del mismo tipo o por medio de inferencias que en últimos término se reducen a tales actos como a sus fundamentos. De qué fuentes puedan surgir tales engaños, esto lo hemos visto ya repetidas veces: cuando, al empatizar, ponemos como base nuestra condición individual en vez de nuestro typos, entonces llegamos a falsos resultados. En principio, en la inferencia por analogía reside la misma fuente de error: también aquí la propia condición fáctica (no típica) constituye el punto de partida; puesto que en lo demás yo procedo lógicamente, no llego a un engaño (esto es, a un supuesto darse originario de lo que de hecho no existente) sino a una conclusión incorrecta sobre la base de la premisa falsa; el resultado es en ambos casos el mismo: un no encontrar lo realmente existente. Ya el 'sano entendimiento humano' considera el 'sacar conclusiones sobre los demás a partir de uno mismo' como un medio no utilizable para alcanzar el conocimiento de la vida anímica ajena.

“Para prevenir tales errores y engaños se requiere una conducción permanente de la empatía por la percepción externa, la constitución del individuo ajeno está enteramente fundada en la constitución del cuerpo físico". El individuo como tal se constituye en su totalidad, como vimos, en actos de empatía. Gracias a esta fundamentación del alma en el cuerpo vivo, la empatía en individuos psicofísicos es posible sólo para un sujeto del mismo tipo. Un puro yo, por ejemplo, para el que no se constituye originariamente un cuerpo vivo propio y una relación psicofísica, quizá podría tener dados objetos varios, pero no podría percibir cuerpos vivos, individuos vivientes...La posibilidad de la percepción interna existe también independientemente de ella, y así la empatía no aparece en este contexto como un constituens, sino sólo como un importante medio auxiliar para la aprehensión del individuo propio (a diferencia de la comprensión del cuerpo vivo propio como de un cuerpo físico como otros, que no sería posible sin empatía).

\section{Conclusión}

1. Resulta decisivo el enfoque metodológico a partir de la 'realidad dada': a diferencia del cuerpo físico -Körper- el cuerpo vivo - Leib- constituido inseparablemente por el yo, que siente, piensa y quiere, es comprendido sólo en la unidad de la percepción externa e interna, a diferencia del cuerpo físico, captado primordialmente por la percepción externa, tanto en lo que se refiere al reposo cuanto al movimiento de esta unidad. Pues, el "cuerpo vivo no sólo está integrado en mi mundo fenoménico, sino es por su parte centro de tal mundo fenoménico, se encuentra frente a 
él y entra en intercambio con él". Esto vale tanto para la corporalidad propia como ajena, ambas analizadas en estricta correlación y unidas por la empatía en cuanto 'puente'.

2. La expresión del cuerpo vivo emerge en interrelación, tanto con los sentimientos como con la voluntad, desde la conciencia, "esa región insuprimible del ser", donde "se encuentran las sensaciones como una especificación de la categoría superior 'vivencia', en cuanto subjetiva compenetrada por la objetiva, ya que la conciencia siempre es conciencia de... en una originariedad dada, que se constituye co-dada cuando entra en juego el yo ajeno. La empatía une ambas originariedades en la novedad de una expresión corporal de la co-originariedad".

3. A través de la expresión constitutiva de la corporalidad viva se plasma la Gemütsart de cada tipo humano, que más allá de comprenderse como temperamento evoca la última profundidad de cada ser humano, que Edith Stein designará con la expresión 'alma del alma' y en relación con la cual la autora definirá lo femenino y la especificidad de la mujer en obras posteriores.

\section{Anneliese MEIS ssps}

Facultad de Teología Pontificia Universidad Católica de Chile ameis@uc.cl 